\title{
Parametric Studies of Non-Prismatic Folded Plate Structures
}

\author{
Dr. Aradhana Mehta ${ }^{1}$ and Aditya Kumar Tiwary ${ }^{2}$ \\ Professor, Civil Engineering Department, Maharaja Agarsen University, Baddi (H.P.) ${ }^{1}$ \\ Assistant Professor, Civil Engineering Department, Chandigarh University, Mohali ${ }^{2}$
}

\begin{abstract}
In this paper the behaviour of non-prismatic folded plate roof with varying design parameters have been studied by taking a specific example of non-prismatic plate roof of administrative block of NIT at Hamirpur, H.P, India. Different design parameters selected for study are plate thickness and different support conditions. It has been observed that the value of deflections are higher for less plate thicknesses while transverse moments, principal stresses and longitudinal moments are lower. When rigid diaphragms are provided at two ends of folded plate, deflections decrease at mid span and quarter span while longitudinal moments increase.
\end{abstract}

Keywords: non-prismatic folded plate, plate thickness, diaphragms, deflections, stresses, moments.

\section{INTRODUCTION}

The special merit of folded plates is that heavy loads can be supported at intersections. In folded plate structures, enclosing surface is itself the main structural system and carries all external loading, thus they are much more economical than conventional truss type roofing system in which cladding is secondary structural system. Because of their rigidity, shuttering can be stripped at the end of seven days resulting in speedier construction. Although they consume a little more of cement and steel compared to shells, the increased cost on this account is more than offset by lower shuttering costs. Thus, folded plates may be regarded as a compromise possessing a large proportion of efficiency of continuously curved shells and at the same time involving low constructional costs. Interest is arising in this type of construction because folded plates are suitable for long spans and its aesthetic appeal. Most of the folded plate structures are prismatic consisting of constant thickness and rise, rectangular plate elements but now construction of non-prismatic folded plates has also gained popularity. In non-prismatic folded plates, each transverse cross section of the structure has different shapes. Need is, therefore, felt to study the behaviour of non-prismatic folded plates with different parametric changes. For present study, dimensions of non-prismatic folded plate to be constructed as roof covering on administrative block building at NIT Hamirpur, have been chosen. Finite element method, due to its high versatility, in handling complex structures is utilized for the analysis. The computer program used is TYRANT.EXE in Fortran IV based on finite element method.

\subsection{Objective}

i. In the present investigation, a non-prismatic folded plate (Figure I) is considered for analysis. It is uniformly loaded to $375 \mathrm{~kg} / \mathrm{m} 2$ including dead load and imposed load. The analysis of this plate is done with different span lengths and different central rises. The spacing between the column supports is $8.2 \mathrm{~m}$.

ii. In the first investigation, structure of folded plate is analyzed for five different plate thicknesses $10.0 \mathrm{~cm}, 12.5 \mathrm{~cm}$, $15.0 \mathrm{~cm}, 17.5 \mathrm{~cm}$ and $20.0 \mathrm{~cm}$ with span length of $21.0 \mathrm{~m}$ and central rise of $2.0 \mathrm{~m}$.

iii. In the second investigation, structure is provided diaphragms at two ends of folded plate with plate thickness $10 \mathrm{~cm}$ and rise of plate as $2.0 \mathrm{~m}$.

\section{METHODOLOGIES}

\subsection{Slab action analysis}

The transverse section of the slab of unit length is analyzed as a continuous beam on rigid supports. The joint loads obtained from this analysis are replaced by their components in the planes of the slabs.

\subsection{Plate action analysis}

Under the action of plate 'loads' obtained above, each slab is assumed to bend independently between the diaphragms and the longitudinal stresses at the edges are calculated. Continuity demands that the longitudinal stresses at the common edges of adjacent slabs be equal. The corrected stresses are obtained by introducing edge shear forces. The transverse moments and stresses developed in non-prismatic folded plates can be considerably large than those in 
corresponding prismatic structures which cover the same horizontal area. Thus to reduce magnitude of stresses add transverse moment, it is advisable to place narrow end of one plate adjacent to wider end of others.

\subsection{Semi-loof element}

In view of the two dimensional behaviour of the plate, a proper choice of finite element analysis is necessary. Normally used finite elements may require a large number of elements to represent the structure. Semi-Loof element is similar to iso-parametric 8-noded parabolic element as shown in figure 1. The element has the capacity to represent the general geometry of thin shells or plates. Any geometry is approximated by the same interpolation function which represents the displacement variations within the isoparametric element.

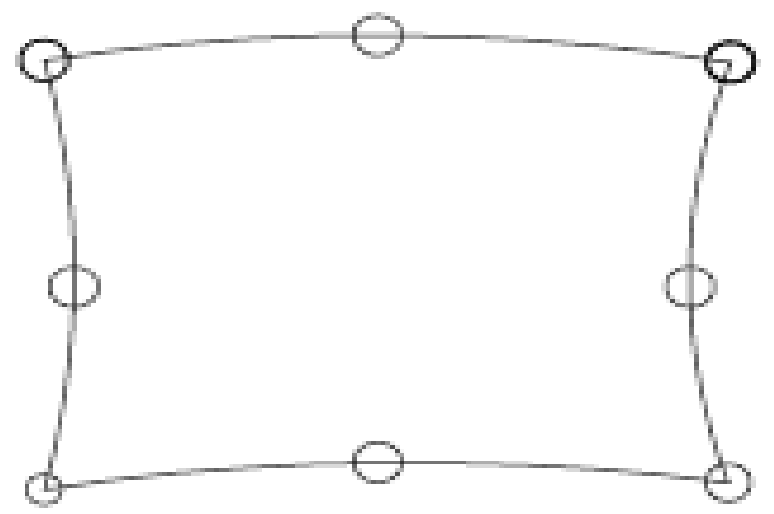

Figure 1 Isoparametric 8 noded parabolic element

\subsubsection{Discretization of continuum}

The given body is sub divided into an equivalent system of finite elements. Elements may be triangular, trapezoidal, isoparametric etc. the elements are connected to each other at nodal points only.

\subsubsection{Selection of displacement models}

A polynomial is more commonly selected as displacement function to represent displacement at any point within the element in terms of the nodal displacements. Polynomial is preferred as it permits differentiation and integration with ease and its easy adaptability to give desired approximation by changing its order.

\subsubsection{Derivation of stiffness matrix using a variational approach}

The stiffness matrix consists of coefficients of equilibrium equations derived from material and geometric properties of an element. The distributed forces applied to the structure are converted into nodal force vector (Fe). The nodal force vector $(\mathrm{Fe})$ and nodal displacement vector $(\delta \mathrm{e})$ are expressed as a set of simultaneous linear algebraic equations.

$$
\left(\mathbf{F}^{\mathrm{e}}\right)=\left(\mathbf{K}^{\mathrm{e}}\right)\left(\boldsymbol{\delta}^{\mathrm{e}}\right)
$$

\subsubsection{Assembly of algebraic equation for overall discretized continuum}

The overall equilibrium relation between the total stiffness matrix $(\mathrm{K})$, the total load vector $(\mathrm{F})$ and nodal displacement vector for the entire body $(\delta)$ will be expressed as a set of simultaneous equations.

$$
(\mathbf{F})=(\mathbf{K})(\boldsymbol{\delta})
$$

\subsubsection{Solution for unknown displacements}

The algebraic equations are solved by known mathematical techniques with the help of boundary conditions to determine the unknown displacements.

\subsubsection{Computations of element strains and stresses}

Once the nodal displacements are known the strains and stresses for each element are determined as these values are related to the derivatives of the displacement. Herein a two dimensional, quadrilateral and triangular type of semi-loof element of 8-node is taken for analysis ad shown in Figure 1. The boundaries have been taken as straight lines for simplicity. The node points are selected as discrete points on the element boundaries. The aim is to get displacements and stress resultants at nodal points. The centre to centre spacing between columns is $8.2 \mathrm{~m}$. To take the advantage of single symmetry, only half of the folded plate is analyzed and line of symmetry is taken on the transverse side of the cross-section figure 2 . 


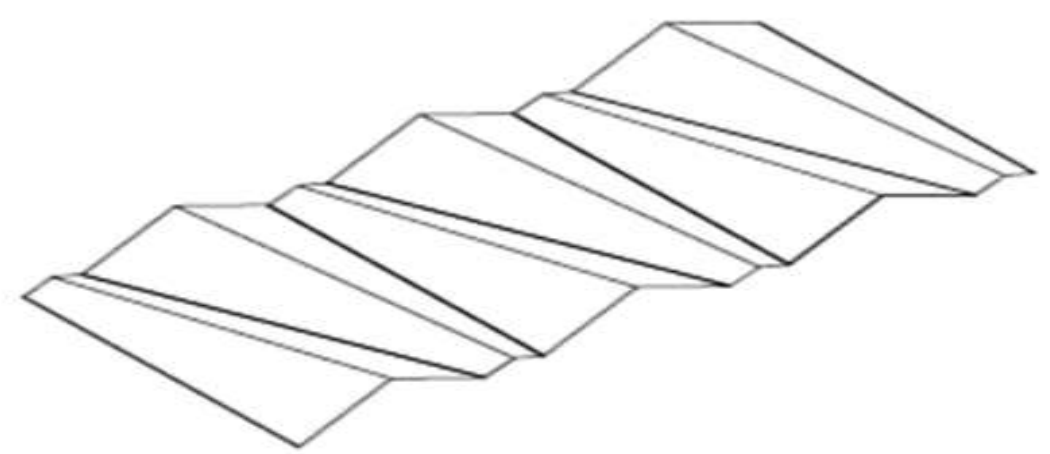

Figure 2 Non-prismatic folded plate roof

\section{RESULTS OF FINITE ELEMENT ANALYSIS}

In the present study, analysis is done for single span non-prismatic folded plate of $21.0 \mathrm{~m}$ span whose deflection and moments go on changing with change in plate thickness and support conditions.

\subsection{Effect of variation in plate thickness of folded plate with constant rise}

Folded plate is supported at four points. No diaphragm is provided at any section. Central rise of folded plate is kept 2.0 $\mathrm{m}$ and five plate thicknesses of $10.0 \mathrm{~cm}, 12.5 \mathrm{~cm}, 15.0 \mathrm{~cm}, 17.5 \mathrm{~cm}$ and $20.0 \mathrm{~cm}$ are are taken for study. Deflections, principal stresses, longitudinal moments and transverse moments are observed at the mid span of folded plate. When plate thicknesses of $10.0 \mathrm{~cm}, 12.5 \mathrm{~cm}, 15.0 \mathrm{~cm}, 17.5 \mathrm{~cm}$ and $20.0 \mathrm{~cm}$ are used with span length of $21.0 \mathrm{~m}$ and central rise of $2.0 \mathrm{~m}$., the maximum deflection at mid span is $14.0 \mathrm{~mm}, 12.0 .0 \mathrm{~mm}$ and $10.0 \mathrm{~mm}, 7.0 \mathrm{~mm}$ and $4.0 \mathrm{~mm}$ respectively. The maximum transverse moments along the mid span of folded plate is $390 \mathrm{~kg}-\mathrm{m}$ and it increases to 600 $\mathrm{kg}-\mathrm{m}$ for $20.0 \mathrm{~cm}$ plate thickness. The maximum longitudinal moment at mid span folded plate is $90 \mathrm{~kg}-\mathrm{m}$ and increases to $112 \mathrm{~kg}-\mathrm{m}$ for $20.0 \mathrm{~cm}$ plate thickness. The maximum principal stress is $1.6 \mathrm{~kg} / \mathrm{cm} 2$ for $10.0 \mathrm{~cm}$ thick plate and increases to $9.3 \mathrm{~kg} / \mathrm{cm} 2$ for $20.0 \mathrm{~cm}$ plate thickness. Results are shown in Table 1.

Table 1 Results with the variation in Plate thickness with 2.0 m central Rise

\begin{tabular}{|c|c|c|c|c|c|c|}
\hline S.No. & $\begin{array}{c}\text { Rise } \\
(\mathrm{m})\end{array}$ & $\begin{array}{c}\text { Plate } \\
\text { thickness } \\
(\mathrm{mm})\end{array}$ & $\begin{array}{c}\text { Maximum } \\
\text { Deflection } \\
(\mathrm{mm})\end{array}$ & $\begin{array}{c}\text { Maximum } \\
\text { Transverse } \\
\text { Moment }(\mathrm{kg}-\mathrm{m})\end{array}$ & $\begin{array}{c}\text { Maximum } \\
\text { Principal Stresses } \\
\left(\mathrm{kg} / \mathrm{cm}^{2}\right)\end{array}$ & $\begin{array}{c}\text { Maximum } \\
\text { Longitudinal } \\
\text { Moments (kg-m) }\end{array}$ \\
\hline 1 & 2.0 & 10.0 & 14.0 & 390 & 1.6 & 90 \\
\hline 2 & 2.0 & 12.5 & 12.0 & 403 & 2.2 & 102 \\
\hline 3 & 2.0 & 15.0 & 10.0 & 479 & 4.2 & 107 \\
\hline 4 & 2.0 & 17.5 & 7.0 & 541 & 5.8 & 110 \\
\hline 5 & 2.0 & 20.0 & 4.0 & 600 & 9.3 & 112 \\
\hline
\end{tabular}

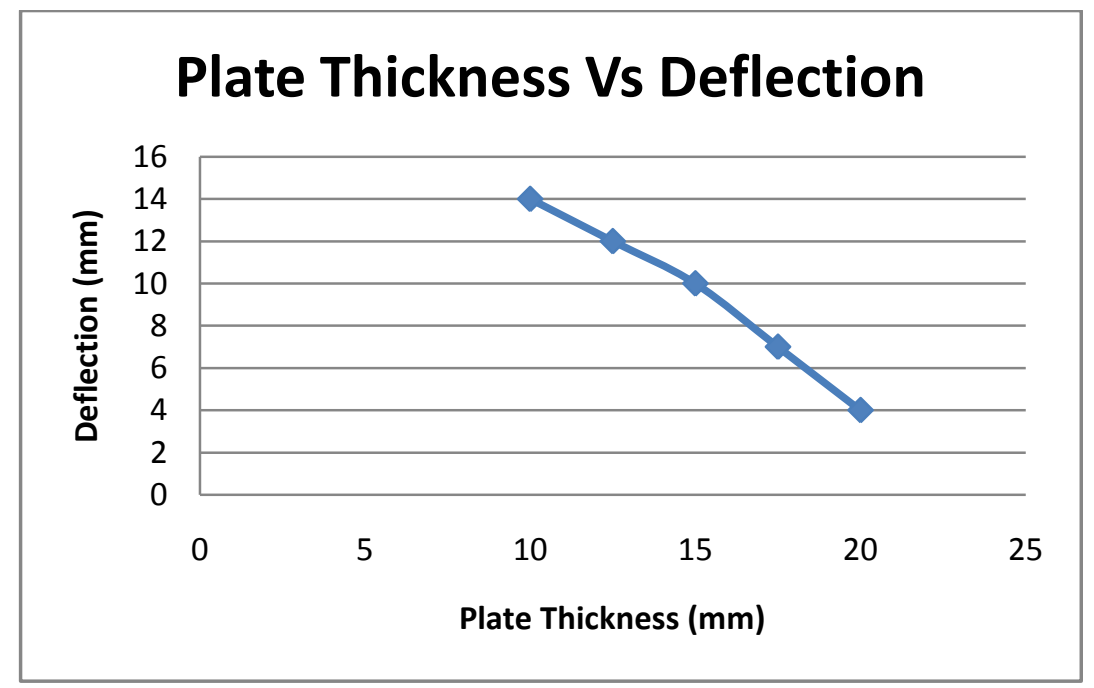

Figure 3 Deflection curve for different plate thickness. 


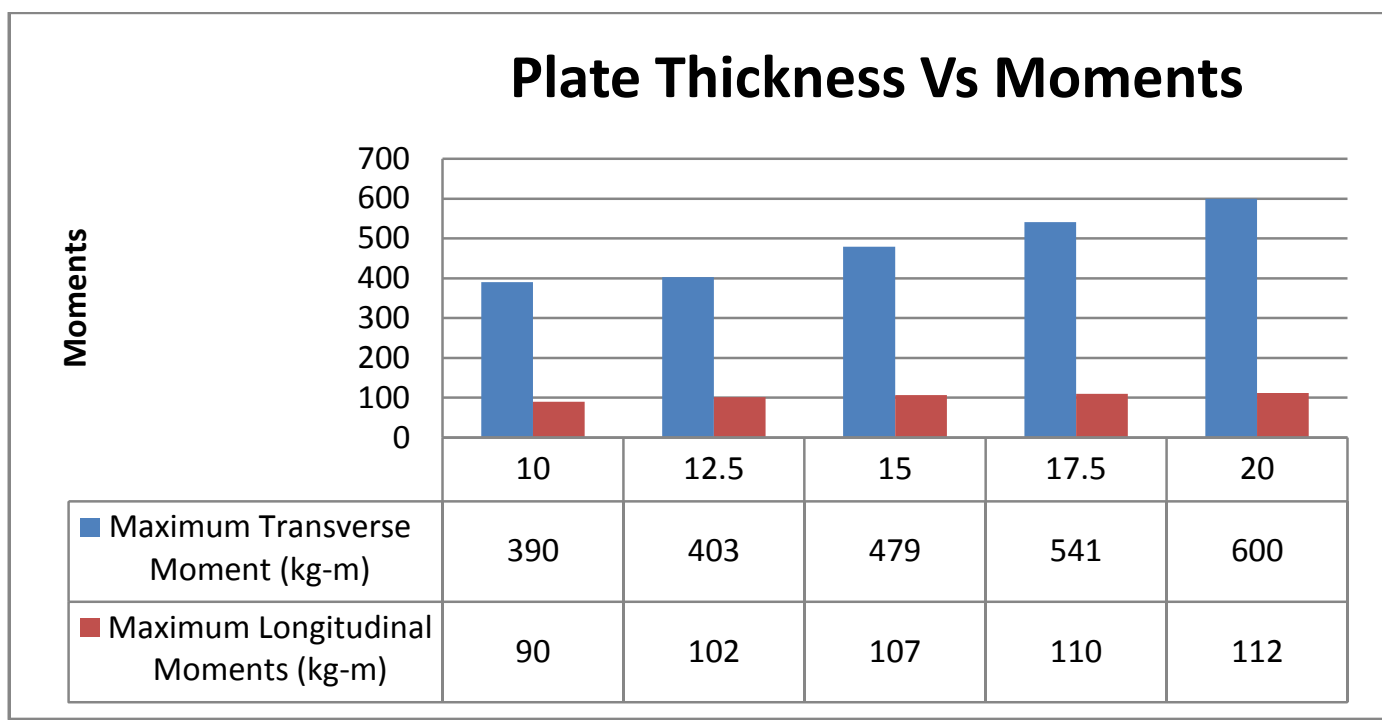

Figure 4 Maximum transverse and longitudinal moment for different plate thickness

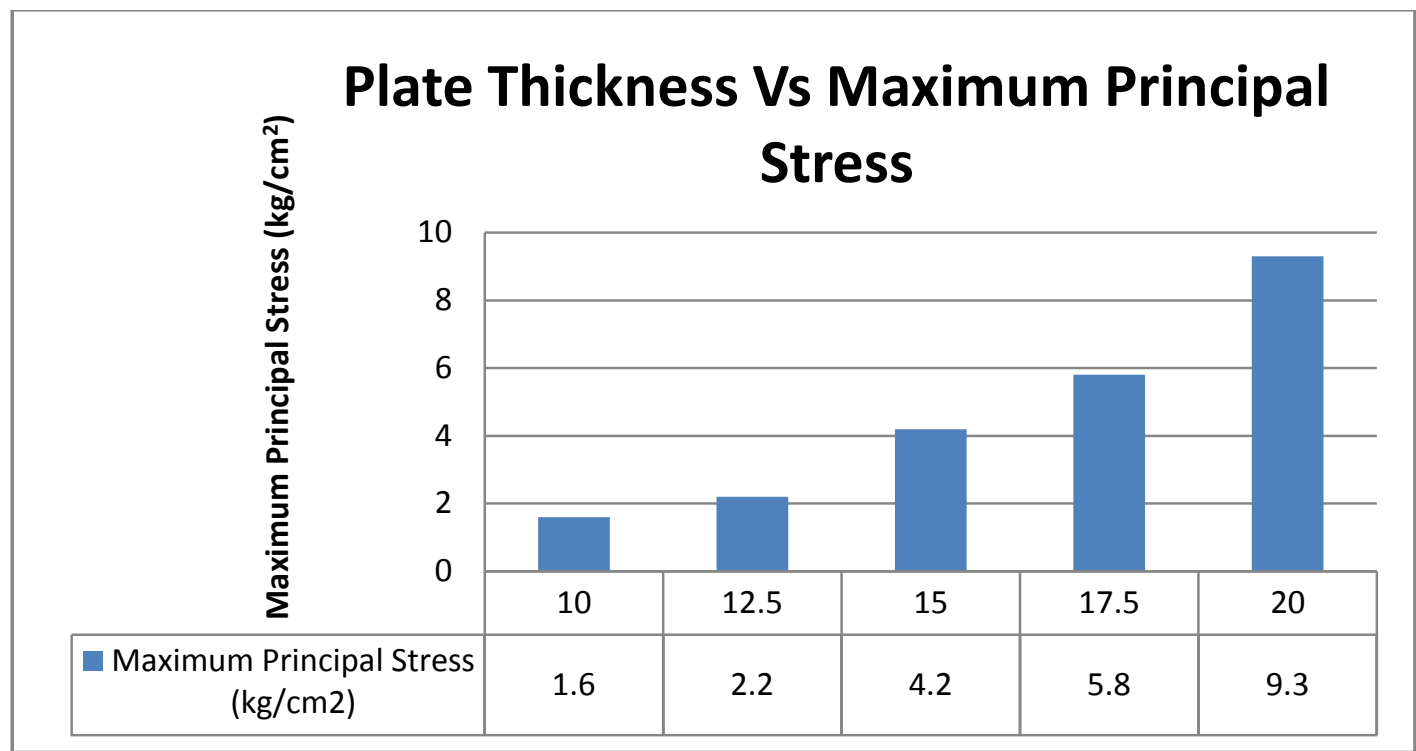

Figure 5 maximum principal stresses for different plate thickness

When plate thickness increases from $10.0 \mathrm{~cm}$ to $20.0 \mathrm{~cm}$, deflection decrease approximately to one third times at mid span. Principal stresses increase and transverse moments also increase. Longitudinal moments also increase for greater plate thicknesses.

The deflections decrease at mid span and quarter span when plate thickness increases from $10.0 \mathrm{~cm}$ to $15.0 \mathrm{~cm}$ and further decrease when plate thickness increases from 15.0 to $20.0 \mathrm{~cm}$. This is due to the fact that with increase in plate thickness, structure becomes stiffer thus decreasing the deflections.

Transverse moments, Principal stresses and longitudinal moments increase by increasing thickness of folded plate thereby increasing the moments and stresses.

\subsection{Effect of providing diaphragms at two ends of folded plate}

In this case, $21.0 \mathrm{~m}$ non-prismatic folded plate is provided with diaphragms at two ends. Plate thickness is kept as 10.0 $\mathrm{cm}$. Folded plate is supported at four points.

For $21.0 \mathrm{~m}$ span with $2.0 \mathrm{~m}$ rise in plate, max deflection is $20.0 \mathrm{~mm}$ at mid span. When diaphragms are provided at the ends, maximum deflection at mid span reduces to $5.9 \mathrm{~mm}$. The deflections at quarter spans also decrease. This is due to the fact that the structure tends to be stiffer in the longitudinal direction thus decreasing the deflections.

The maximum principal stress is $4.9 \mathrm{~kg} / \mathrm{cm}^{2}$ which decrease to $2.55 \mathrm{~kg} / \mathrm{cm}^{2}$ when diaphragms are provided at the ends of folded plate. Principal stresses decrease at all the other points. This is due to the increased stiffness of the folded 


\section{IARJSET

plate in the longitudinal direction. Maximum transverse moments along the mid span of folded plate is $561 \mathrm{~kg}-\mathrm{m}$ and it decreases to $431 \mathrm{~kg}-\mathrm{m}$ at the same point when diaphragms are provided. This is due to the fact that the structure tends to be stiffer in the longitudinal direction thus decreasing the transverse moments. It is observed that the maximum longitudinal moments increase by providing diaphragms at two ends of folded plate.

\section{CONCLUSIONS}

In the present investigations, a non-prismatic folded plate roof is analyzed by varying design parameters namely plate thickness and end conditions of nonprismatic folded plate. Deflections, principal stresses, transverse moments and longitudinal moments are observed at mid section of the span. The main conclusions arising from this study are given below:

i. With decrease in plate thickness from $12.5 \mathrm{~cm}$ to $10.0 \mathrm{~cm}$, deflections increase at mid span and quarter span while transverse moments, longitudinal moments and principal stresses decrease. This is due to the fact that with decrease in thickness of plate, stiffness decreases, so deflections increase but due to less dead weight of the plate, moments and stresses get reduced. With increase in plate thickness from 15.0 to $20.0 \mathrm{~cm}$, deflections decrease whereas transverse moments, longitudinal moments and principal stresses become higher.

ii. When rigid diaphragms are provided at two ends of folded plate, deflections become lower by $60-70 \%$ at mid span and quarter span while longitudinal moments become higher. Transverse moments get reduced by $20-25 \%$ and principal stresses decrease by $40-50 \%$.

\section{REFERENCES}

[1] Fialkow, M.N., Oct.1972,"Safe Limit loading of folded plate structures"Journ. of Struc.Divn. ASCE.

[2] Failkow, M.N., July 1975,"Plastic collapse of folded plate structures”Journ. Of Struc.Divn, ASCE, pp. 1559-1584.

[3] Goble, G.G., Feb. 1964, “Analysis of folded plate structures” Journ. Struc. Divn, pp. 93-124.

[4] Ibrahim, I.M. and Monferton, G.R. May 1979, "Finite strip laminated sandwich roof analysis", Journ. Struc. Divn. ASCE, pp. 905-919.

[5] Rockey, K.C. and Evans, H.R., June 1971, “A critical review of the methods of analysis of folded plate structures"Journ. Institution of Engineers, pp. 171-191.

[6] Seetharumulu, K. and Sinha, S.N. July 1979, “Tests on microcrete continuous folded plates” Journ. Struc. Divn. ASCE, pp. 1457-1470.

[7] Wahab, A.A. and Mousa, A.A., Oct. 1979, "Folded Plates with intermediate supports,"Journ.Struc. Divn. ASCE, Pp 151-172

[8] Raj Kumar, C., 1973, "Elastic Analysis of Short Span Continuous Floded Plates," Ph.D. Thesis Submitted to I.I.T. Delhi.

[9] Victor, F.H. and Ellgin, F., July 1979, “Assemblage method for folded plate Analysis,” Journ.Struc.Divn.ASCE, Vol.105, pp.1509-1524

[10] "Criteria for Design of Reinforced Concrete Shell Structures and Folded Plates" IS 2210:1962.

[11] Scordelis, A.C., Croy, E.L. and Stubbe, I.R., Dec. 1961,"Experimental and Analytical study of folded plate” Journal struc. Divn. ASCE, Vol. 87, pp 139-160.

[12] Ramaiah, M. , May 1966, “Computer Analysis of folded plate by method of transfer matrices” Journal of Institution of Engrs (India), pp. 140161. 